\title{
MIKRO TURBIN ANGIN AERODINAMIKA KENDARAAN SEBAGAI SUMBER ENERGI LISTRIK AKUMULATOR KENDARAAN BERMOTOR
}

\section{Micro Wind Turbine Aerodynamics of Vehicles as a Source of Electrical Energy for Motor Vehicles Accumulators}

\author{
Fabian Roshan ${ }^{1, *}$, Andrian', Irkhas Ismaya Ramadhanu1 \\ ${ }^{1}$ Jurusan Teknologi Pertanian - Fakultas Pertanian - Universitas Jenderal Soedirman \\ *Korespondensi, Email: fabianroshan09@gmail.com \\ DOI: https://doi.org/10.20884/1.jaber.2021.2.1.4099 \\ Naskah ini diterima pada 14 April 2021; revisi pada 23 April 2020; \\ disetujui untuk dipublikasikan pada 11 Mei 2021
}

\begin{abstract}
ABSTRAK
Banyaknya energi yang terbuang pada kendaraan yang mencapai 87,40\% menyebabkan energi yang dapat dipakai hanya sedikit yaitu 12,60\% sedangkan untuk beban energi yang diperlukan pada kendaraan cukup besar yaitu 77,92 watt. Pemanfaatan energi angin aerodinamika pada kendaraan menjadi salah satu cara untuk menghemat penggunaan bahan bakar dan akumulator sehingga diharapkan dapat memenuhi kebutuhan energi pada setiap komponen kendaraan. Berdasarkan pada persamaan yang sudah ada pada penelitian sebelumnya dihasilkan bahwa daya 4 mikro turbin dapat mencapai 10,84 watt dengan arus listrik 1,81 ampere. Persamaan yang digunakan adalah persamaan daya dan persamaan arus. Potensi mikro turbin yang dapat dimanfaatkan adalah pemanfataan waste energy (energi yang terbuang), penunjang energi listrik kendaraan, kendaraan lancar melaju, bentuk desain yang sederhana, menambah estetika kendaraan, dan harga produk ekonomis.
\end{abstract}

Kata kunci: angin aerodinamika, beban energi, energi terbuang

\begin{abstract}
The amount of energy wasted on vehicles up to $87.40 \%$ would cause consumption of just a fraction of 12.6 percent, whereas the required energy load on vehicles would be 77.92 watts. The use of aerodynamic wind energy in vehicles is one way to conserve fuel and accumulator so that it is expected to meet the energy requirements of each vehicle component. Based on the similarities already found in previous studies, the power of 4 micro turbines can reach 10,84 watts with a 1,81 amps. The equations used are the power equation and the current equation. The potential for micro-turbines that can be utilized is the use of waste energy, supporting electric vehicle energy, vehicles running smoothly, simple design forms, adding to vehicle aesthetics, and economical product prices.
\end{abstract}

Keywords: energy load, wasted energy, wind aerodynamics

\section{PENDAHULUAN}

Permasalahan banyaknya beban energi pada kendaraan bermotor yang cukup banyak diperlukan adanya suplai energi alternatif agar dapat meminimalkan penggunaan bahan bakar minyak. Menurut Putra (2014), beban energi kendaraan bermotor terbagi menjadi 3, yaitu energi pembakaran, energi pendinginan, dan energi kelistrikan, yang sumber energi utamanya berasal dari bahan bakar minyak. Ketiga energi tersebut, yang menjadi sumber energi utama adalah energi pembakaran. Menurut Haworth, et al. (2001), energi yang digunakan pada kendaraan 
bermotor hanya $12,60 \%$ yang termanfaatkan dari proses pembakaran hingga ke beban kendaraan bermotor dan sisanya terbuang dalam bentuk panas buang.

Berdasarkan data yang dihasilkan dari bahan bakar, maka energi yang terpakai dari masing-masing bahan bakar kendaraan bermotor ketika digunakan pada kendaraan bermotor adalah sebesar 12,60\%, yaitu 844,8 watt; 832 watt; dan 819,2 watt. Energi yang dihasilkan dari proses pembakaran bahan bakar minyak, aliran energi akan mengalir ke beban kendaraan, yaitu energi kelistrikan kendaraan. Menurut Saputra (2018), beban energi kendaraan bermotor diantaranya adalah lampu depan, lampu belakang, lampu tanda belok, lampu indikator, dan klakson. Energi yang digunakan mencapai 77,92 watt.

Selain bersumber dari energi pembakaran, beban energi kendaraan juga didukung oleh akumulator. Kapasitas akumulator setiap kendaraan tentunya bermacam-macam. Namun, apabila penggunaannya dilakukan secara terus- menerus, maka hal itu dapat menyebabkan pemborosan bahan bakar dan pemborosan energi listrik akumulator. Hal itu disebabkan sumber energi kendaraan diawali dengan bahan bakar dan kapasitas akumlator yang terbatas (Sembiring, 2010).

Salah satu pemanfataan energi alternatif sebagai energi untuk mendukung kelistrikan kendaraan bermotor salah satunya adalah energi angin aerodinamika kendaraan bermotor. Namun, pemanfaatan energi angin aerodinamika berdasarkan penelitian Anggraini et al. (2016), masih menggunakan satu turbin, tidak menggunakan penyetabil arus dan tegangan, dan pemanfaatan hanya dilakukan pada lampu di luar komponen kendaraan. Padahal, energi maksimum yang dihasilkan mencapai 6,96 watt dan tegangan 11,5 volt dengan kecepatan kendaraan $50 \mathrm{~km} / \mathrm{jam}$. Oleh karena itu, jika dimanfaatkan sebagai sumber arus untuk akumulator sangat potensial dan akan lebih banyak termanfaatkan energinya selain untuk lampu.

Berdasarkan permasalahan tersebut, maka penulis tertarik untuk melakukan penelitian dengan tujuan: (1) Mendesain mikro turbin angin aerodinamics untuk kendaraan bermotor sebagai pendukung sumber energi listrik akumulato dan (2) Mensimulasikan perhitungan energi listrik mikro turbin angin pada kendaraan bermotor.

\section{METODE PENELITIAN}

\section{Alat dan Bahan}

Alat yang digunakan dalam penelitian ini adalah software Slidworks 2014, Kinemaster, dan Knapwing. Sedangkan bahan yang digunakan dalam penelitian ini adalah data sekunder terkait kecepatan kendaraan, data angin aerodinamika kendaraan bermotor, dan data karakteristik akumulator yang didapatkan dari buku dan jurnal.

\section{Metode Penelitian}

Gambar 1 menunjukkan tahapan peneltian dimana diawali dengan pengumpulan data. Pengumpulan data ini dilakukan dengan mencari sumber-sumber data dari buku dan jurnal untuk menunjang proses kegiatan. Sumber data yang di dapat dari tahap ini digunakan sebagai data sekunder dalam pembuatan mikro turbin, yaitu data kecepatan kendaraan, data data angin aerodinamika kendaraan bermotor, dan data karakteristik akumulator.

Ketika data sudah terkumpul, kemudian diolah dengan metode perhitungan matematis dilakukan menggunakan rumus daya mikro turbin dan rumus waktu pengisian akumulator. Berikut ini adalah persamaan rumus tersebut:

Persamaan daya mikro turbin:

$$
\mathrm{P}=\mathrm{Cp} \times \mathrm{NB} \times \mathrm{NG} \times 1 / 2 \times \rho \times \mathrm{A} \times \mathrm{v}^{3}
$$

Persamaan arus mikro turbin:

$\mathrm{I}=\mathrm{P}: \mathrm{V}$ 

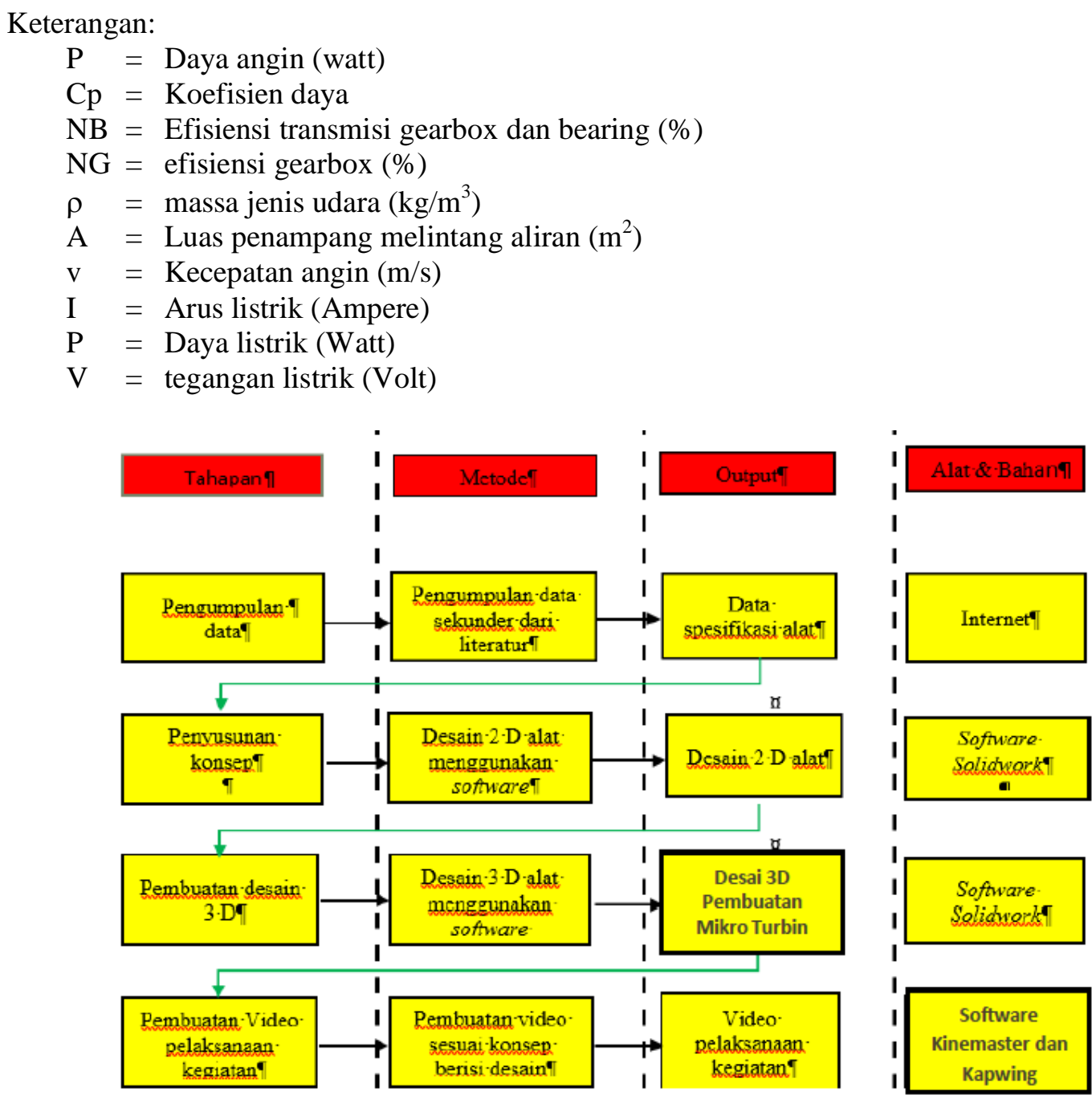

Gambar 1. Diagram alir metode penelitian

Tahap selanjutnya dilanjutkan dengan penyusunan konsep. Penyusunan konsep dilakukan setelah menyelesaikan tahap pengum- pulan data. Data-data yang telah dikumpulkan terutama data terkait kelebihan dan kekurangan perkembangan teknologi yang sudah ada. Kemudian, dibuat inovasi dari teknologi yang sudah ada untuk memperbaiki keku- rangan tersebut. Selanjutnya dibuat desain sementara berupa desain $2 \mathrm{D}$ untuk menentukan dimensi dimensi alat.

Tahap ketiga adalah pembuatan desain 3 dimensi. Pembuatan desain 3 dimensi dari data yang telah dikumpulkan dengan menggunakan software 3 dimensi Solidworks 2014 sehingga didapatkan desain 3 dimensi alat pembuat mirko turbin.

Kemudian dilajutkan dengan tahapan terakhir yaitu pembuatan video. Pembuatan video dari data yang telah dikumpulkan dengan menggunakan aplikasi Kinemaster dan Kapwing, yang bertujuan untuk membuat video pelaksanaan kegiatan sebagai bentuk luaran penelitian. 


\section{HASIL DAN PEMBAHASAN}

Hasil yang dicapai adalah desain 3 dimensi mikro turbin dengan diameter turbin 3 inchi atau 7,62 cm, 3 baling-baling, dan panjang dudukan turbin $25 \mathrm{~cm}$ (Gambar 2, dan 3).

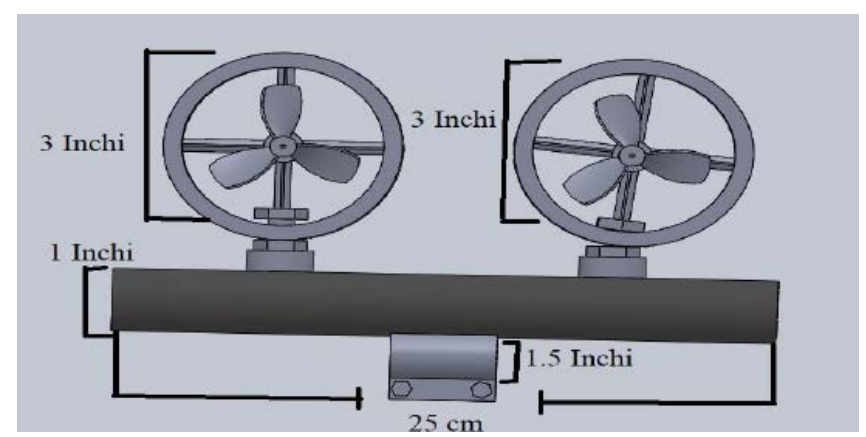

Gambar 2. Desain mikro turbin

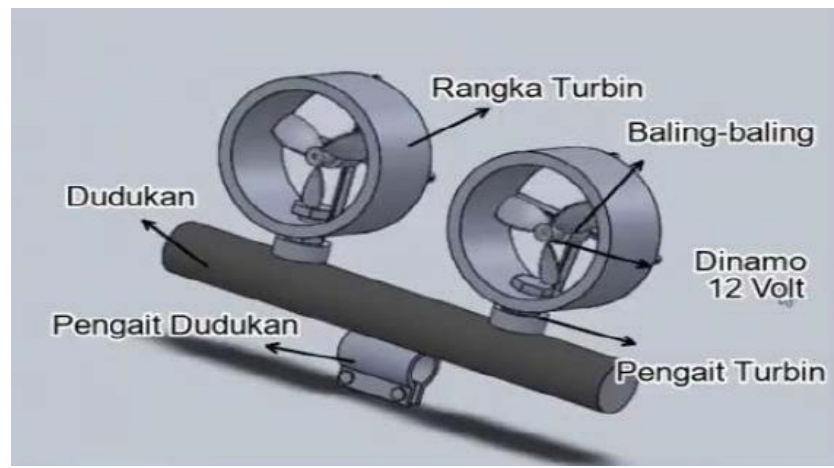

Gambar 3. Desain mikro turbin

Data diameter turbin digunakan untuk menghitung daya mikro turbin dan daya mengacu pada data kecepatan angin. Kecepatan angin diperoleh dari tujuh puluh persen dari kecepatan kendaraan. Untuk memperoleh daya turbin, maka digunakan rumus daya mikro turbin (Tabel 1).

Tabel 1.

Perolehan daya berdasarkan kecepatan kendaraan

\begin{tabular}{cccccc}
\hline $\begin{array}{c}\text { Kecepatan } \\
\text { kendaraan } \\
(\mathrm{km} . \mathrm{jam})\end{array}$ & $\begin{array}{c}\text { Kecepatan angin } \\
(\mathrm{km} / \mathrm{jam})\end{array}$ & $\begin{array}{c}\text { Kecepatan angin } \\
(\mathrm{m} / \mathrm{s})\end{array}$ & $\begin{array}{c}\text { Daya 1 } \\
\text { turbin } \\
(\text { watt })\end{array}$ & $\begin{array}{c}\text { Daya 2 } \\
\text { turbin } \\
(\text { watt })\end{array}$ & $\begin{array}{c}\text { Daya 4 } \\
\text { turbin } \\
\text { (watt) }\end{array}$ \\
\hline 10 & 7 & 1,94 & 0,00 & 0,00 & 0,00 \\
20 & 14 & 3,89 & 1,08 & 2,17 & 4,34 \\
30 & 21 & 5,83 & 1,63 & 3,25 & 6,50 \\
40 & 28 & 7,78 & 2,17 & 4,34 & 8,68 \\
50 & 35 & 9,72 & 2,71 & 5,42 & 10,84 \\
60 & 42 & 11,67 & 3,25 & 6,51 & 13,01 \\
70 & 49 & 13,61 & 3,79 & 7,59 & 15,18 \\
80 & 56 & 15,56 & 4,34 & 8,68 & 17,35 \\
\hline
\end{tabular}

Setelah daya mikro turbin diperoleh, daya digunakan untuk menentukan arus dan kapasitas terisi yang digunakan pada akumulator. Tegangan digunakan 6 volt dan 12 volt. Nilai arus dapat diperoleh dengan rumus daya dibagi tegangan. Kemudian arus yang dihasilkan dapat digunakan untuk memperoleh kapasitas terisi menggunakan rumus waktu pengisian akumulator (Tabel 2 dan Tabel 3). 
Tabel 2.

Penerapan daya dan arus dari turbin ke akumulator (tegangan 6 volt)

\begin{tabular}{cccccc}
\hline $\begin{array}{c}\text { Kecepatan } \\
\text { angin (m/s) }\end{array}$ & $\begin{array}{c}\text { Daya 4 turbin } \\
\text { (watt) }\end{array}$ & Tegangan (volt) & $\begin{array}{c}\text { Arus } \\
\text { (Ampere) }\end{array}$ & $\begin{array}{c}\text { Waktu } \\
\text { (jam) }\end{array}$ & $\begin{array}{c}\text { Kapasitas } \\
\text { terisi (Ah) }\end{array}$ \\
\hline 1,94 & 0,00 & 6 & 0,00 & 1 & 0,00 \\
3,89 & 4,34 & 6 & 0,72 & 1 & 0,72 \\
5,83 & 6,50 & 6 & 1,08 & 1 & 1,08 \\
7,78 & 8,68 & 6 & 1,45 & 1 & 1,45 \\
9,72 & 10,84 & 6 & 1,81 & 1 & 1,81 \\
11,67 & 13,01 & 6 & 2,17 & 1 & 2,17 \\
13,61 & 15,18 & 6 & 2,53 & 1 & 2,53 \\
15,56 & 17,35 & 6 & 2,89 & 1 & 2,89 \\
\hline
\end{tabular}

Tabel 3.

Penerapan daya dan arus dari turbin ke akumulator (tegangan 12 volt)

\begin{tabular}{cccccc}
\hline $\begin{array}{c}\text { Kecepatan } \\
\text { angin }(\mathrm{m} / \mathrm{s})\end{array}$ & $\begin{array}{c}\text { Daya } 4 \text { turbin } \\
\text { (watt) }\end{array}$ & Tegangan (volt) & $\begin{array}{c}\text { Arus } \\
\text { (Ampere) }\end{array}$ & $\begin{array}{c}\text { Waktu } \\
\text { (jam) }\end{array}$ & $\begin{array}{c}\text { Kapasitas } \\
\text { terisi (Ah) }\end{array}$ \\
\hline 1,94 & 0,00 & 12 & 0,00 & 1 & 0,00 \\
3,89 & 4,34 & 12 & 0,36 & 1 & 0,36 \\
5,83 & 6,50 & 12 & 0,54 & 1 & 0,54 \\
7,78 & 8,68 & 12 & 0,72 & 1 & 0,72 \\
9,72 & 10,84 & 12 & 0,90 & 1 & 0,90 \\
11,67 & 13,01 & 12 & 1,08 & 1 & 1,08 \\
13,61 & 15,18 & 12 & 1,27 & 1 & 1,27 \\
15,56 & 17,35 & 12 & 1,45 & 1 & 1,45 \\
\hline
\end{tabular}

Video pelaksanaan penelitian terkait Mikro Turbin Angin Aerodinamika Kendaraan Sebagai Sumber Energi Listrik Akumulator Kendaraan Bermotor tercantum pada link: https://m.youtube.com/watch?v=GPY_LwV5Ztc

Berdasarkan hasil yang dicapai, terdapat potensi khusus yang menjadikan mikro turbin dapat diaplikasikan pada kendaraan bermotor. Pada video simulasi penerapan mikro turbin, jumlah turbin yang digunakan adalah 4 turbin yang dirangkai paralel. Pada sepeda motor, mikro turbin dirangkai secara 2 mikro turbin disebelah kanan dan 2 lainnya disebelah kiri. Adapun pada mobil, mikro turbin dirangkai secara bersama keempat turbinnya.

Pemanfaatan mikro turbin agar lebih maksimum, tentunya dimanfaatkan pada kendaraan bebas hambatan, seperti jalan raya maupun jalan tol. Hal itu disebabkan kecepatan kendaraan pada jalan tersebut mencapai lebih dari $50 \mathrm{~km} / \mathrm{jam}$. Energi listrik yang dihasilkan mikro turbin dapat dihitung dengan energi yang dihasilkan setiap 1 jam dikalikan dengan berapa lama kendaraan bermotor melaju. Hal itu disebabkan ketika pengendara melakukan, besarnya angin aerodinamika dan daya yang dihasilkan mikro turbin bergantung pada kecepatan kendaraan dan lamanya berkendara.

\section{KESIMPULAN}

Berdasarkan uraian hasil yang dicapai, maka kesimpulan yang diperoleh adalah: (1) Konstruksi (konfigurasi) mikro turbin 4 unit diameter $(\varnothing) 7,62 \mathrm{~cm}$ secara paralel menghasilkan daya listrik sebesar 10,81 watt dan arus listrik 1,81 Ampere dan (2) Mikro turbin dapat digunakan untuk peralatan dalam kendaraan bermotor (lampu kendaraan, charger, akumulator eksternal) tanpa terhubung ke regulator kendaraan. 


\section{DAFTAR PUSTAKA}

Anggraini, F., A. Surtono, \& G. H. Pauzi. (2016). Pemanfaatan Energi Angin Pada Sepeda Motor Bergerak Untuk Menyalakan Lampu. Jurnal Teori dan Aplikasi Fisika, 4 (02), 167-174.

Aryanto, M. I., Made, M., \& Made, N. (2013). Pengaruh Kecepatan Angin dan Variasi Jumlah Sudu Terhadap Unjuk Kerja Turbin Angin Poros Horizontal. Dinamika Teknik Mesin, 3(1), 50-59.

Budiman, W., Nasrun, H., \& Syahrial. (2014). Perancangan dan Realisasi Sistem Pengisian Baterai 12 Volt 45 Ah pada Pembangkit Listrik Tenaga Pikohidro di UPI Bandung. Jurnal Reka Elkomika, 2(1), 112.

Maryanto. (2010). Termodinamika. Yogyakarta, Indonesia: Universitas Negeri Yogyakarta.

Mulyono, S., Gunawan, \& Budha M. 2013. Pengaruh Penggunaan dan Perhitungan Efisiensi Bahan Bakar Premium dan Pertamax Terhadap Unjuk Kerja Motor Bakar Bensin. Jurnal Teknologi Terpadu, 2(1), 28-35.

Putra, R. S. (2014). Analisa Cover Sub Assy Battery Untuk Kendaraan Bermotor Roda Empat. JTM, 03(3),19-26.

Sembiring \& David, JM. (2010). Pengaruh Penyalaan Lampu Sepeda Motor Pada Siang Hari Terhadap Konsumsi BBM. Medan, Indonesia: STT Poliprofesi. 